\title{
Understanding the Occupational Burnout Experience of Medical Specialists at the Time of Education and Career Launch: A Case Study of the Sechenov First Moscow State Medical University Students and Residents of the Alekseev Psychiatric Hospital N1
}

\author{
Anzhela Avagimyan*(D), Nataliya Kasimovskaya (D), Olga Naryzhenko (D), Ekaterina Diatlova (D), Raisat Adzhimuradova (D), \\ Nadezhda Nikishina \\ Department of Nursing Management and Social Work, Sechenov First Moscow State Medical University, Moscow,
} Russian Federation

Edited by: Sinisa Stojanosk Citation: Avagimyan A, Kasimovskaya N, Naryzhenko O, Diatlova E, Adzhimuradova R, Nikishina N Understanding the Occupational Burnout Experience of Medical A Case Study of the Sechenov First Moscow State Medical University Students and Residents of the Alekseev Psychiatric Hospital N1. Open-Access Maced J Med Sci. 2022 Jan 01; 10(E):40-49 https://doi.org/10.3889/oamjms.2022.773 Keywords: Balinn groups, Nurses, Occupational burnou Psychiatrists; Residents; Student *Correspond Moscow State Medical University, Moscow, Russian Federation. E-mail: avagimyanan@rambler.ru Received: $28-0 c t-202$ Revised: 06-Dec-202 Copyright: @ 2022 Anzhela Avagimyan, Nataliya Kasimovskaya, Olga Naryzhenko, Nadezhimuradova,

Funding: This research did not receive any financia Competing Interest: The authors have declared that no competing interest exist

Open Access: This is an open-access article distributed under the terms of the Creative Commons AttributionNonCommercial 4.0 International License (CC BY-NC 4.0)

\begin{abstract}
BACKGROUND: Occupational burnout in the most general terms is seen as a long-lasting stressful situation resulting from continuing occupational stress of moderate intensity.

AIM: The objective of this article is to provide analysis of occupational burnout in psychiatrists and nurses of psychiatric hospitals, and the development of occupational burnout in students and residents.

MATERIALS AND METHODS: The level of occupational burnout was determined using the "Attitude to work and occupational burnout" test, Seashore Group Cohesion Index, Stolin's Self-Concept Questionnaire, and the Freiburg Multidimensional Personality Questionnaire (Freiburg Personality Inventory). The study proved the existence of patterns of occupational burnout in psychiatrists and nurses of psychiatric hospitals, as well as in students and residents.

RESULTS: It has been revealed that the development of the burnout syndrome is influenced by personal qualities of psychiatrists and nurses (residents and students), and the managerial features of their activities, and that occupational burnout develops in psychiatrists and nurses over the course of their professional careers, but starts to emerge during their education. The score of the Integrative Burnout Index ranges from 48.99 in students of the [BLINDED] University to 23.52 in psychiatrists of the Alekseev Psychiatric Hospital N1. Occupational burnout syndrome is spread in medical students worldwide, with its level higher than in the overall population, in students of other specialties.
\end{abstract}

CONCLUSIONS: Burnout at the stage of getting the education can hinder the professional development of students, expose patients to risk, and promote the development of various personality problems in future psychiatrists and nurses. The need of preventing professional burnout at the stage of obtaining a specialty has been substantiated.

\section{Introduction}

Today, occupational burnout in the most general terms is seen as a long-lasting stressful situation resulting from continuing occupational stress of moderate intensity. Therefore, the syndrome of psychic burnout is defined by a number of authors as an occupational (emotional) exhaustion, which allows for the insight into this phenomenon in terms of personal deformity of a specialist under the influence of the long-lasting working experience. [1].

Professional activity of medical workers, involved in the treatment and rehabilitation of patients, is related to a high degree of responsibility for life and health of patients, often requiring fast decision-making, and the ability to preserve the high working efficiency under the emotional tension. Therefore, psychiatrists and nurses fall under the risk of occupational burnout, which negatively affects both their mental health, performance, and their relationship with people around them. Today, the studies on occupational burnout cover psychiatrists and nurses specializing in various fields anesthesiologists [2], paramedics [3], and psychiatrists of palliative care [4].

Until now, there is no single objective division of various syndromes and symptom complexes, united by the general concept of "burnout." Various authors write about the "burnout" as a state of exhaustion combined with the feeling of one's own irrelevance, uselessness. According to the views of Maslach et al. [5], burnout syndrome is seen as a response to long-term professional stresses arising in interpersonal relationships; - "emotional burnout" (according to Boiko [6]) as a personality developed mechanism of psychological defense in the form of complete or partial exclusion of emotions in response to selected psychotraumatic influences; - "professional burnout" as 
a syndrome that develops against the background of chronic stress and leads to depletion of the emotional, energy, and personal resources of a working person; and - "mental burnout" as a phenomenon of the negative impact of the profession on the personality, in the form of a complete regression of professional development, since it affects the personality as a whole, destroying it and having a negative impact on the efficiency of labor activity. According to the WHO definition, burnout syndrome is not only physical, emotional, or motivational exhaustion, characterized by impaired productivity at work, fatigue, and insomnia but also an increased susceptibility to physical illness (and the risk of developing physiological dependence on alcohol or other psychoactive drugs used for temporary relief and suicidal behavior) [7], [8]. Regarding the definition of the place of burnout among impalements of professional genesis, there are opinions that this is a form of occupational deformation, a particular manifestation of maladaptation, and occupational disease. We will take a closer look at this in the literature review.

Issues of emotional burnout of psychiatrists and nurses of psychiatric service are under lively discussion. The statistics received indicate escalated dissatisfaction with professional achievements among the employees of mental health centers, symptoms of depersonalization, and reduced empathy skills. Analysis of research papers shows that the issue of occupational burnout among nurses in psychiatrics has been largely left uncovered while it is the nursing staff that is prevalently engaged with patients, thus being at risk [9].

Studying the problems of providing professional assistance to students of medical schools during their education becomes the most important task today focusing on creating favorable conditions for their further successful career in medicine [10]. The assistance in fighting occupational burnout shall be provided to future psychiatrists and nurses of mental health centers precisely from the beginning, that is, from their medical schools. There is a similar experience abroad involving medical students in educational Balint groups.

Applying the concept of burnout to medical students is relatively recent. Assessments of prevalence of occupational burnout in medical students vary significantly in the studies. A research [10] presents the international experience from 24 studies encompassing 17,431 medical students. The current prevalence is estimated to be $40.8 \%$.

Therefore, due to the significant prevalence of occupational burnout during the professional development of future medical workers, searching for reasons for this phenomenon and the means to cope with it becomes very topical in contemporary world. Our research aims at studying the specifics of occupational burnout development in medical students (future nurses) and residents (future psychiatrists), and comparing this phenomenon with occupational burnout in medical workers - nurses and psychiatrists already employed in mental health.

The objective of the research is to study the phenomenon of occupational burnout among mental health residents as compared to medical students, that is, future nurses.

\section{Literature review}

Studies of occupational burnout (the syndrome of emotional exhaustion) in specialists of caring professions widespread in the early 1980s. Initially, the majority of the research papers included the collection of empirical data in the particular field and various means of struggle with emerging problems [11]. Since 1981, when Maslach jointly with Jackson offered a threefactor model of emotional burnout and the Maslach Burnout Inventory questionnaire as a diagnostic tool for quantifying emotional burnout widely used today, the range of professions studied has expanded, involving individuals, employed in the legal, educational, medical, and other fields along with social workers [12], [13]. The emergence of symptoms of occupational burnout has been observed among the teaching staff of medical universities. Symptoms were even more severe among psychiatrists involved in teaching rather than among those engaged in teaching only [14]. Overtime, signs of burnout started to be detected in people outside of their professional activities, for example, in sports, political activity, and studies [15].

Much research has been devoted to identifying factors of occupational burnout in nurses since they particularly are exposed to this syndrome [16], [17]. Studies have identified factors of resistance to burnout [18]. These include (a) high level of job autonomy (freedom to take initiative and make decisions), (b) internal locus of control, and (c) management support. Thus, the risk of burnout is lower for employees who identify themselves with their work, have higher levels of self-efficacy, and positive emotional relationships with management [19].

Since 2000, the study of occupational burnout has entered the "meta-analyses stage," a formal sign of which the authors consider a change in the relative and absolute number of literature reviews in the general pool of thematic publications, and the very fact of the onset of this stage, from their viewpoint, is a sign of sufficient accumulation of knowledge for research on the etiology and pathogenesis of burnout [1].

According to the study on occupational burnout in medical students, the prevalence has been estimated to be $44.2 \%$ [10]. Geographic location (i.e. the country where the study was conducted) also matters. Thus, a higher prevalence is observed in Oceania and the Middle East as compared to South/Central America and Europe. That being said, the key factors promoting profession burnout in medical students in any country 
include academic stress related to competitiveness, examination period, tuition fee payment, and working conditions [6]. High prevalence of emotional exhaustion in medical students is linked to depression and anxiety that can explain the high prevalence of these psychic symptoms, and be the risk factors for depression in the work-related following years. Burnout was also linked to anxiety, smoking, and drinking alcohol, using antidepressants and suicidal thoughts [14], [20].

The problem of distinguishing the phenomenon of mental burnout from other psychological disorders still remains relevant [21]. Work stress, depression, occupational deformation, occupational destruction, anxiety, anomie, chronic fatigue syndrome, etc., are distinguished among the states and processes that are similar in symptomatology.

Domestic experience is presented in studies by Ognerubov and Karpova [22], and Zrazhevskaya et al. [15]. The studies show that the education of medical students is influenced by various circumstances and facts including not only the peculiarities of the medical profession associated with constant selfcontrol, nervous tension, and responsibility for other lives but also the problems common in students of any other professions. This can bring us to the conclusion that medical students are prone to psychoemotional distress, which later on may become the basis for the development of occupational burnout.

Coping with dangerous symptoms during one's student years is of particular importance for training specialists within psychiatry, since in the future, specialists of this particular profile are exposed to a great risk of the development of occupational burnout in the Russian Federation [23], [24] and abroad [9], [20].

Aggregated results of the studies on means of coping with occupational burnout in medical students from 1990 to 2015 show high prevalence in students, with a level higher than in the overall population. Burnout can hinder the professional development of students, expose patients to risk, and promote the development of various personality problems including suicidal thoughts. Factors of educational and working environment are the main burnout factors, and to cope with it, one would need multilateral efforts with due consideration of social and cultural specifics, conditions of education and work, as well as individual behavior [25].

Impact assessment of emotional intelligence and professional communication parameters in preventing occupational burnout is a modern trend today. Emotional intelligence plays an important role in combating burnout, and you can improve emotional intelligence abilities through specific training programs, useful to promote the ability to cope with stress and to enrich the relationships in the workplace [26], [27].

Conducting Balint groups are a common way of coping with occupational burnout health care professionals, although today in our country, they are less popular than, for example, 1 time training. Balint groups can be recommended as a long-term program for the prevention and control of symptoms of occupational burnout in specialists of caring professions, including the stage of developing professional skills.

\section{Materials and Methods}

\section{Research design}

For 6 years, we have been implementing the "Balint Groups in Psychiatry" project. Balint group is a method of a group training research used for preventing occupational burnout. This method is named after the psychoanalyst Michael Balint who used to hold training seminars at the Tavistock Clinic in London for practicing physicians and psychiatrists in 1949. The experience was first described in the book The Psychiatrist, his Patient and the Illness (1957). Initially, the groups were intended for medical professionals, but today they are used to assist specialists of caring professions (teachers, psychologists, police officers, social workers, etc.)

We conducted Balint groups in 2015-2016 with nurses and senior nurses at the premises of Gilyarovsky Psychiatric Hospital N3. Since 2017, we have been conducting Balint groups with psychiatrists, heads of departments, medical psychologists, senior nurses, and nurses at the premises of the Alekseev Psychiatric Hospital N1. This project is being implemented under the auspices of the medical director of the Alekseev Psychiatric Hospital N1 and the senior psychiatrist of Moscow, Prof. Georgi Kostyuk.

In 2017-2018 together with our colleagues Leyko and Sarkisova, we conducted a large-scale study in the Alekseev Psychiatric Hospital N1 on the impact of origin of Balint groups on preventing occupational burnout in psychiatry specialists - psychiatrists, medical psychologists, nurses, and senior nurses [28], [29].

In 2018-2020, this study was complimented by conducting Balint groups among residents of the $1^{\text {st }}$ and $2^{\text {nd }}$ years involving 50 males and females in total of the average age 24-26. In 2020, eight $2^{\text {nd }}$ year students completed their Balint Group Leaders training course, and in May 2021, seven residents will be completing the same course.

Moreover, within 6 years [BLINDED] delivered 61 presentations for students of medical, pediatric, pharmaceutical, and senior nursing departments.

\section{Sample}

The study involved 38 psychiatrists, 97 nurses, and 50 residents of the $1^{\text {st }}$ and $2^{\text {nd }}$ years of the Alekseev 
Psychiatric Hospital N1, and $1231^{\text {st }}$ year students of the Chair of Social Activity Management and Social Work, Institute of Psychological and Social Work, the [BLINDED] University, during the period of 2017-2020.

Involvement in the study was voluntary, and the majority of participants were also taking part in the Balint groups under the "Balint Groups in Psychiatry" Project, in the introductory Balint groups at the [BLINDED] University or the Balint Group Leaders Training Course for residents of the Alekseev Psychiatric Hospital N1.

The study considered four research group according to the area of specialization: Psychiatrists, psychiatry residents, nurses, and students.

\section{Data analysis}

Intersectional narrative and comparative statistical analyses were conducted using the IBM SPSS Statistics 20 software. The study considered the Pearson correlation coefficient - a method of parametric statistics that allows you to determine the presence or absence of a linear relationship between two quantitative indicators, as well as to evaluate its tightness and statistical significance, and Student's t-test for independent samples which is used to compare the means of two independent groups. Application conditions: The compared values do not constitute a pair of correlated values. The distribution of features in each sample corresponds to a normal distribution. To check the equality of variances, the Levene test is used which is more resistant to violation of the normal distribution than other tests; the SPSS software automatically carries out Levene's test when running the t-test. The null hypothesis of Levene's test is the variances are equal across the population.

\section{Ethical issues}

The study was conducted by interviewing subjects that participated voluntarily. The ethical clearance was obtained from the Sechenov First Moscow State Medical University № 5-19.

\section{Research measuring instrument}

A method battery was used to determine the degree of occupational burnout. Particularly, the questionnaire "Attitude to work and occupational burnout" (AWOB), Seashore Group Cohesion Index, Stolin's Self-Concept Questionnaire (SCQ), and the Freiburg Multidimensional Personality Questionnaire were used to determine the degree of occupational burnout.

"AWOB" questionnaire to assess occupational burnout in caring professions in nine scales was proposed by Vinokur and Klitsenko [30].
SCQ is developed based on the hierarchical model of self-concept by Stolin [31]. This version of the questionnaire allows us to identify three levels of selfconcept varying in the generalization degree:

1. Global self-concept;

2. Self-concept differentiated by self-esteem, auto-sympathy, self-interest, and expectations of attitude toward oneself;

3. The level of specific actions (readiness for them) in relation to your own "self."

45-55 scores - the average norm. A person adequately perceives oneself and correctly evaluates one's behavior.

self-concept.

55-70 scores - overestimated level of

40-45 cores - underestimated level of self-concept.

The Freiburg Multifactor Personal Questionnaire (Freiburg Personality Inventory [FPI]) is designed to diagnose states and personality traits that are of paramount importance for the process of social adaptation and behavior regulation. FPI technique was developed taking into consideration the experience of structuring and applying such well-known questionnaires as Cattell's 16PF, Minnesota Multiphasic Personality Inventory, Eysenck Personality Inventory. The FPI test is used for psychodiagnostics, career guidance, psychological counseling, expertise, etc. FPI questionnaire contains 12 scales diagnosing neuroticism, spontaneous aggressiveness, depressiveness, irritability, sociability, balance, reactive aggressiveness, shyness, openness, extroversion-introversion, emotional lability, and masculinity-femininity. The total number of questions in the questionnaire is 114 (form B) [32].

Seashore Group Cohesion Index allows for the assessment of the degree of the group integration, its cohesion into a whole.

Working hypotheses of our study can be formulated as follows:

1. Personal qualities of psychiatrists and nurses (psychiatry residents and students) and the managerial features of their activities can impact the development of the burnout syndrome;

2. Occupational burnout develops in psychiatrists and nurses over the course of their professional careers, but it starts to emerge during their education.

\section{Results}

The level of occupational burnout corresponds to that of civil servants in a 2012 study [26], and the 
score of the Integrative Burnout Index ranges from 48.99 in students of the [BLINDED] University to 23.52 in psychiatrists of the Alekseev Psychiatric Hospital $\mathrm{N} 1$, thus, corresponding to the moderate level of occupational burnout.

Comparing the study results of psychiatrists and of residents, we can note the following significant discrepancies under the AWOB test (Table 1 and Figure 1).

Table 1: Attitude to work and occupational burnout test (doctors vs. residents)

\begin{tabular}{|c|c|c|c|c|c|}
\hline Scale & Residents & Doctors & $\mathrm{t}$ & $\mathrm{F}$ & Significance \\
\hline Emotional exhaustion & 46.65 & 45.12 & 0.65 & 0.330 & 0.567 \\
\hline Tension at work & 42.79 & 43.32 & -0.21 & 11.490 & 0.001 \\
\hline Job satisfaction & 39.23 & 42.03 & -0.95 & 1.329 & 0.252 \\
\hline Occupational perfectionism & 50.80 & 46.44 & 1.81 & 0.225 & 0.636 \\
\hline $\begin{array}{l}\text { Self-assessment of the work } \\
\text { quality }\end{array}$ & 46.62 & 39.59 & 2.73 & 0.096 & 0.757 \\
\hline $\begin{array}{l}\text { Aid and psychological } \\
\text { support of colleagues at work }\end{array}$ & 45.80 & 43.35 & 0.75 & 5.288 & 0.024 \\
\hline $\begin{array}{l}\text { Professional development } \\
\text { and self-actualization }\end{array}$ & 36.07 & 38.80 & -1.04 & 0.007 & 0.932 \\
\hline General self-concept & 50.12 & 41.43 & 3.76 & 0.023 & 0.879 \\
\hline $\begin{array}{l}\text { Health and general } \\
\text { adaptation }\end{array}$ & 46.57 & 44.47 & 0.69 & 3.227 & 0.076 \\
\hline Integrative burnout index & 46.76 & 43.52 & 1.76 & 3.241 & 0.075 \\
\hline
\end{tabular}

The questionnaire includes the following scales:

1. Emotional exhaustion;

2. Tension at work;

3. Job satisfaction and assessment of its significance;

4. Occupational perfectionism;

5. Self-assessment of the work quality;

6. Aid and psychological support of colleagues at work;

7. Professional development and self-actualization;

8. General self-concept;

9. Health and general adaptation.j

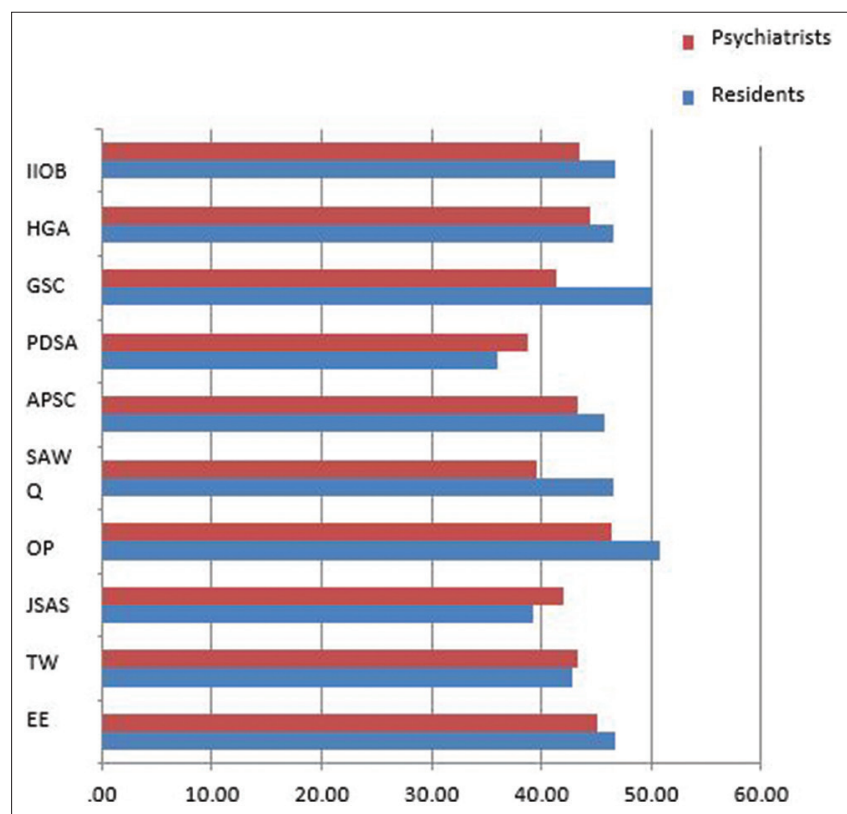

Figure 1: Attitude to work and occupational burnout test (doctors vs. residents)
The following significant discrepancies were obtained on the scale "General self-concept" $(t=3.76$, $p=0.0$ ) and on the scale "Self-assessment of the work quality" ( $t=2.73, p=0.07$ ) (higher in residents). Thus, underestimated self-concept, general assessment, and assessment of professional activity contribute to an increase of the level of occupational burnout in residents.

FPI test allowed to obtain the following significant discrepancies as presented in Table 2 and Figure 2.

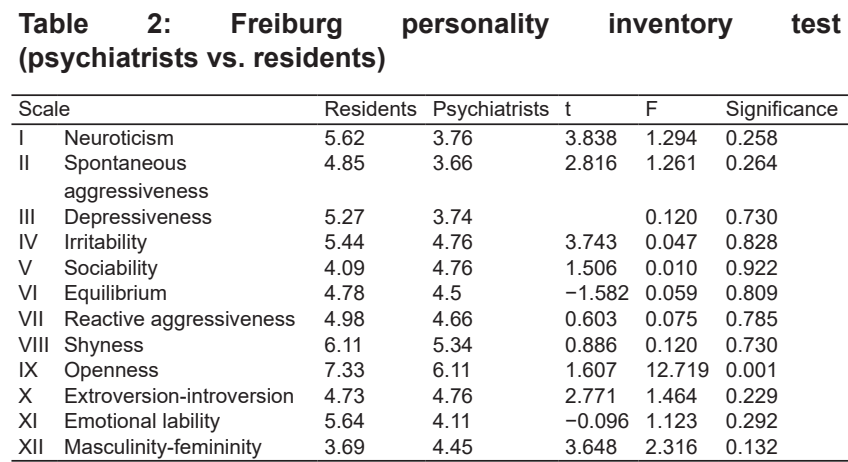

Data obtained speak for a significantly higher level of neuroticism $(t=3.83, p=0.0)$, spontaneous aggressiveness $(t=2.81, p=0.06)$, depressiveness $(t=$ $3.73, p=0.0)$, and emotional lability $(t=3.64, p=0.0)$ in residents, meaning that residents being at the outbreak of their professional career are much more neuroticized due to the stress related both to their education and entering into the profession.

Stolin's SCQ revealed the following significant discrepancies (Figure 3 and Table 3).

The findings of the study show that variables of psychologists significantly differ from variables of residents prevailing them on the following scales:

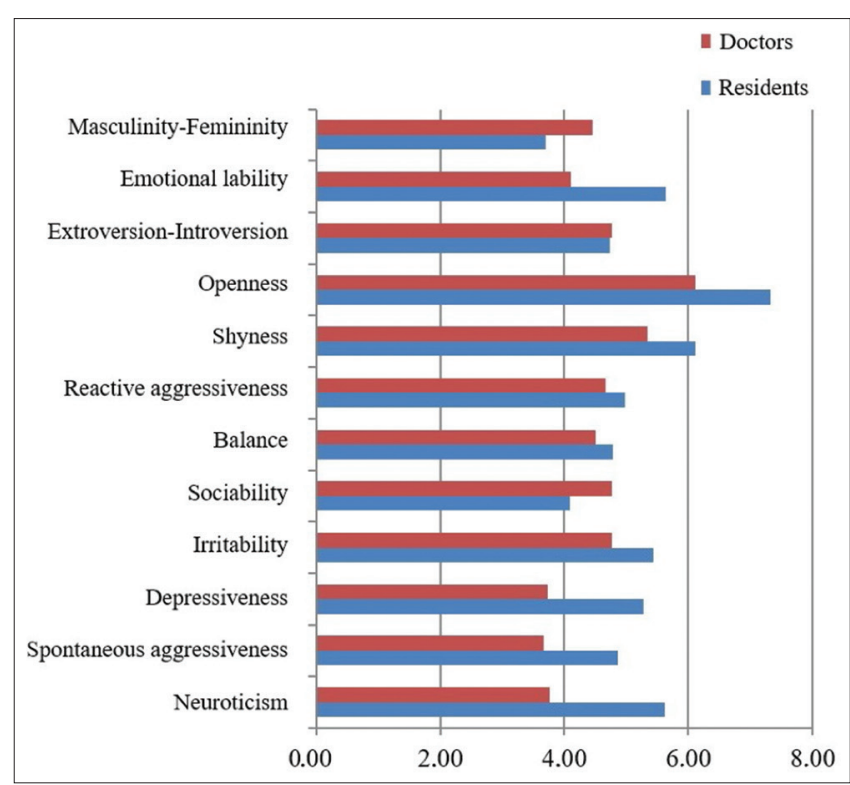

Figure 2: Freiburg personality inventory test (psychiatrists vs. residents) 


\begin{tabular}{|c|c|c|c|c|c|}
\hline \multicolumn{3}{|c|}{$\begin{array}{l}\text { Table } 3: \quad \text { Self-concept } \\
\text { (psychiatrists vs. residents) }\end{array}$} & \multicolumn{2}{|c|}{ questionnaire } & \multirow[b]{2}{*}{ Significance } \\
\hline Scale & Residents & Psychiatrists & $t$ & $\mathrm{~F}$ & \\
\hline $\mathrm{S}$ & 75.13 & 89.02 & -3.045 & 6.443 & 0.013 \\
\hline I & 70.19 & 84.15 & -2.759 & 13.174 & 0.000 \\
\hline II & 70.73 & 83.43 & -2.867 & 1.364 & 0.246 \\
\hline III & 59.41 & 62.41 & -0.600 & 0.385 & 0.536 \\
\hline IV & 53.29 & 53.04 & 0.055 & 1.192 & 0.278 \\
\hline 1 & 63.73 & 80.35 & -3.320 & 0.345 & 0.559 \\
\hline 2 & 56 & 44.84 & 2.309 & 2.354 & 0.128 \\
\hline 3 & 74.22 & 74.69 & -0.116 & 0.381 & 0.539 \\
\hline 4 & 64.88 & 70.21 & -1.162 & 4.396 & 0.039 \\
\hline 5 & 58.03 & 38.66 & 3.060 & 0.622 & 0.432 \\
\hline 6 & 63.32 & 63.61 & -0.056 & 0.241 & 0.624 \\
\hline 7 & 73.29 & 89.03 & -3.882 & 17.716 & 0.000 \\
\hline
\end{tabular}

Scale S - global self-concept; measures the integral feeling "for" or "against" the subject's own "self" $(\mathrm{t}=-3.04, \mathrm{p}=0.0)$.

Scale I - self-esteem $(t=-2.75, p=0.0)$.

Scale II - auto-sympathy ( $\mathrm{t}=-2.86, \mathrm{p}=0.0)$.

Scale 1 - self-confidence $(t=-3.32, p=0.0)$;

Scale 7 - self-understanding $(t=-3.88, p=0.0)$.

Worthy to note two scales where the variables of residents significantly prevail over the variables of psychiatrists:

Scale 2 - attitude of others $(t=2.30, p=0.02)$; Scale 5 - self-reproach $(t=3.06, p=0.0)$.

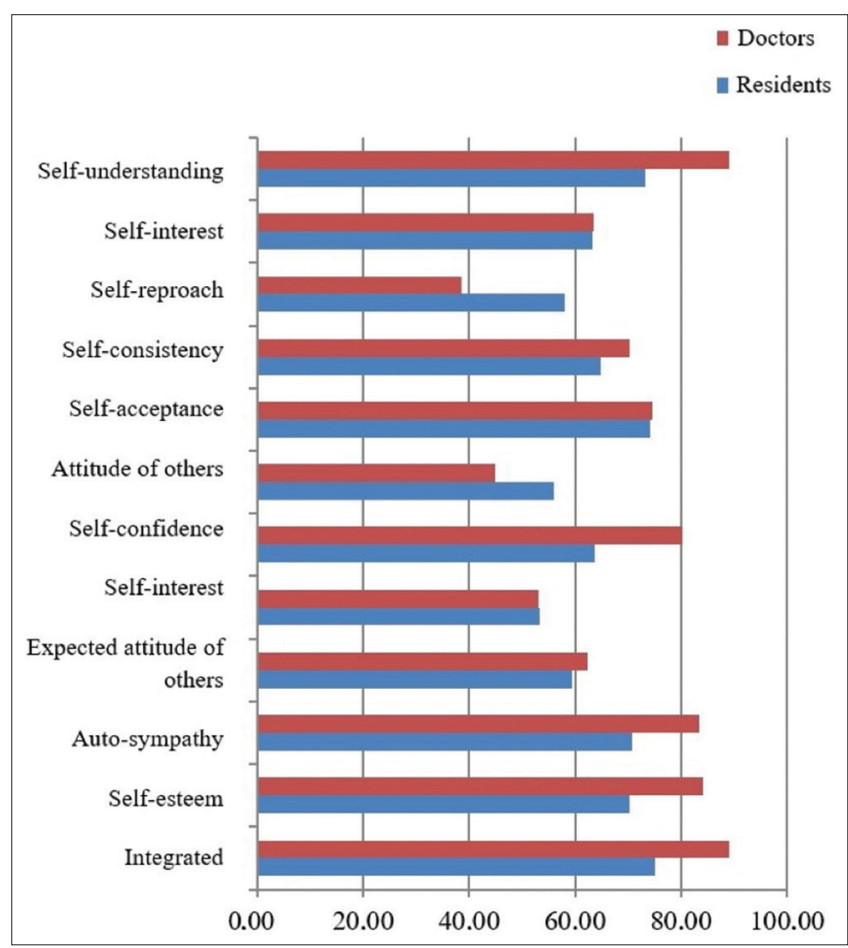

Figure 3: Self-concept questionnaire test (psychiatrists vs. residents)

To wrap up the results of the study, we can state that psychiatrists have a much higher degree of self-concept (partially due to their age and relevant experience), and the prevailing level on the following scales: Self-esteem, auto-sympathy, self-confidence, and self-understanding (a sense of competence in these areas beyond the possibility). All these may be resulting from the professional deformation. On the same scales (particularly selfesteem, auto-sympathy, and self-understanding) residents have ultimately high results, close to reliability levels.

Seashore test is aimed at determining the mediated group cohesion of the team and can be applied to the assessment of both the established professional team and the students' group. Analyses of variables of residents and psychiatrists revealed the following discrepancies:

- $\quad$ Moving to another group $(t=4.48, p=0.0)$

- $\quad$ Quality of group relationships $(t=2.33, p=0.0)$

- Relationship with management $(t=2.96$, $p=0.0$ ).

According to these scales (as well as the rest of the scales including the general index of group cohesion), variables of residents are higher than those of psychiatrists, that is, they evaluate their group as a more integral one.

Comparing the study results of nurses of the Alekseev Psychiatric Hospital N1 and of the $1^{\text {st }}$ year students of the [BLINDED] University, we can see the following data (Table 4 and Figure 4).

Table 4: Attitude to work and occupational burnout test (nurses vs. students)

\begin{tabular}{|c|c|c|c|c|c|}
\hline Scale & Students & Nurses & $\mathrm{t}$ & $\mathrm{F}$ & Significance \\
\hline Emotional exhaustion & 50.48 & 50.30 & 0.11 & 7.379 & 0.007 \\
\hline Tension at work & 46.98 & 49.42 & -1.34 & 4.341 & 0.038 \\
\hline Job satisfaction & 41.48 & 44.54 & -1.42 & 2.230 & 0.137 \\
\hline Occupational perfectionism & 55.87 & 52.42 & 2.57 & 0.103 & 0.749 \\
\hline $\begin{array}{l}\text { Self-assessment of the work } \\
\text { quality }\end{array}$ & 47.29 & 42.82 & 2.64 & 0.715 & 0.399 \\
\hline $\begin{array}{l}\text { Aid and psychological support } \\
\text { of colleagues at work }\end{array}$ & 50.28 & 44.87 & 2.81 & 0.021 & 0.885 \\
\hline $\begin{array}{l}\text { Professional development } \\
\text { and self-actualization }\end{array}$ & 39.80 & 40.78 & -0.47 & 1.818 & 0.179 \\
\hline General self-concept & 48.74 & 45.11 & 2.14 & 6.625 & 0.011 \\
\hline $\begin{array}{l}\text { Health and general } \\
\text { adaptation }\end{array}$ & 50.42 & 50.18 & 0.11 & 2.731 & 0.100 \\
\hline Integrative burnout index & 48.99 & 48.21 & 0.58 & 7.847 & 0.006 \\
\hline
\end{tabular}

The AWOB test revealed the following significant discrepancies on the scales "Occupational perfectionism" $(t=2.57, p=0.01)$, "General self-concept" $(t=2.14, p=0.03)$, "Self-assessment of the work quality" $(t=2.64, p=0.0)$, and "Aid and psychological support of colleagues at work" ( $t=2.81, p=0.05$ ) (with students

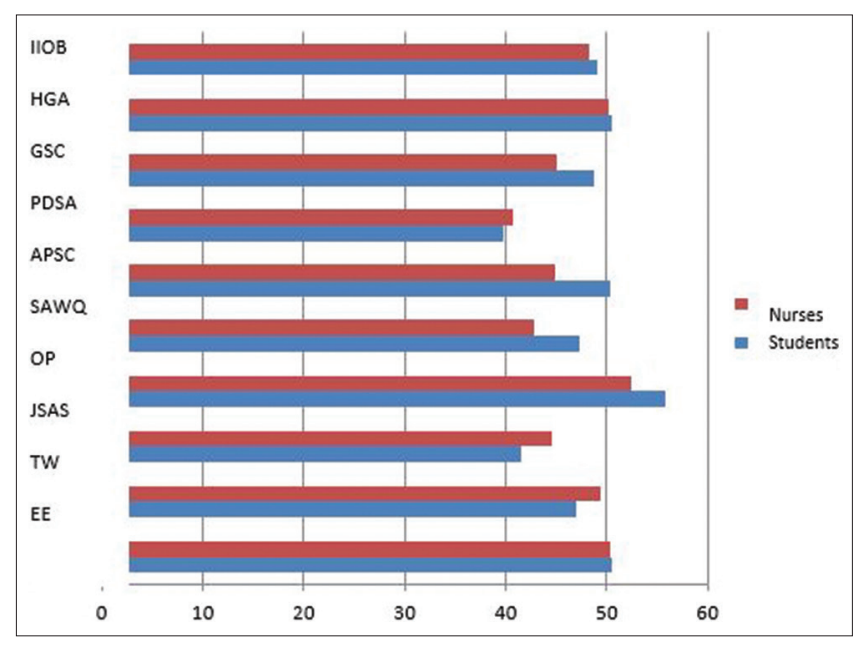

Figure 4: Attitude to work and occupational burnout test (nurses vs. students) 
acquiring higher scores). Thus, a feeling of insufficient professional development makes a greater contribution to the increase of the level of occupational burnout in nurses, and low self-esteem (among other factors insignificant for residents) contributes to an increase of the level of occupational burnout of students.

Table 5: Freiburg personality inventory test (nurses vs. students)

\begin{tabular}{lllllll}
\hline Scale & & Students & Nurses & $\mathrm{t}$ & $\mathrm{F}$ & Significance \\
\hline I & Neuroticism & 6.59 & 4.8 & 6.196 & 3.945 & 0.048 \\
II & Spontaneous aggressiveness & 5.36 & 3.89 & 5.26 & 0.913 & 0.340 \\
III & Depressiveness & 6.25 & 4.63 & 6.677 & 5.023 & 0.026 \\
IV & Irritability & 6.34 & 5.18 & 4.36 & 4.084 & 0.044 \\
V & Sociability & 4 & 4.22 & -0.840 & 0.298 & 0.586 \\
VI & Equilibrium & 4.93 & 4.8 & 0.508 & 2.136 & 0.145 \\
VII & Reactive aggressiveness & 5.84 & 4.72 & 4.647 & 0.971 & 0.326 \\
VIII & Shyness & 6.67 & 6.18 & 1.687 & 4.836 & 0.029 \\
IX & Openness & 6.51 & 6.17 & 1.193 & 1.274 & 0.260 \\
X & Extroversion-introversion & 4.6 & 4.62 & -0.097 & 0.005 & 0.945 \\
XI & Emotional lability & 6.37 & 4.8 & 6.517 & 2.366 & 0.125 \\
XII & Masculinity-femininity & 3.88 & 4.41 & -1.784 & 0.009 & 0.923 \\
\hline
\end{tabular}

According to the Freiburg Multifactor Personal Questionnaire (FPI), the following significant discrepancies were obtained (Table 5 and Figure 5).

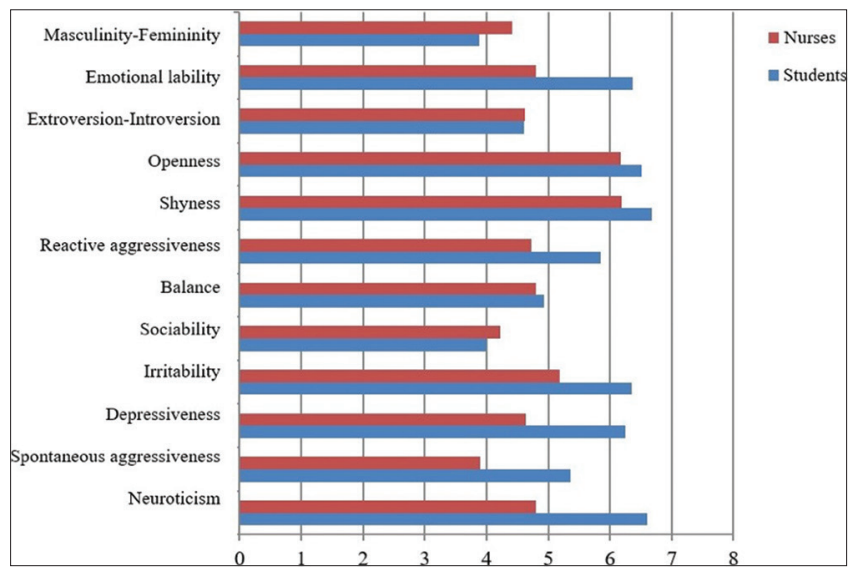

Figure 5: Freiburg personality inventory test (nurses vs. students)

Data obtained speak for a significantly higher level of neuroticism ( $t=6.20, p=0.0)$, spontaneous aggressiveness $(t=5.27, p=0.0)$, depressiveness $(t=6.67, p=0.0)$, emotional lability $(t=6.52, p=0.0)$, irritation $(t=4.37, p=0.0$, and reactive $(t=4.65, p=0.0)$ in students of the [BLINDED] University, meaning that students being at the outbreak of their professional career are much more neuroticized due to the stress related both to their education and entering into the profession.

The SCQ revealed the following significant discrepancies (Table 6 and Figure 6).

Table 6: Self-concept questionnaire test (nurses vs. students)

\begin{tabular}{llllll}
\hline Scale & Students & Nurses & t & F & Significance \\
\hline S & 76.43 & 84.95 & -3.077 & 6.948 & 0.009 \\
I & 66.19 & 77.08 & -3.430 & 1.882 & 0.171 \\
II & 68.71 & 77.11 & -2.841 & 4.646 & 0.032 \\
III & 50.45 & 63.35 & -3.725 & 0.518 & 0.472 \\
IV & 55.03 & 50.5 & 1.606 & 0.078 & 0.781 \\
1 & 59.34 & 76.29 & -4.904 & 4.701 & 0.031 \\
2 & 42.73 & 46.68 & -1.351 & 1.238 & 0.267 \\
3 & 69.16 & 73.54 & -1.324 & 0.359 & 0.550 \\
4 & 62.2 & 67.11 & -1.714 & 0.631 & 0.428 \\
5 & 53.64 & 49.53 & 1.085 & 5.586 & 0.019 \\
6 & 60.32 & 63.36 & -.904 & 4.731 & 0.031 \\
7 & 75.88 & 82.73 & -2.292 & 8.358 & 0.004 \\
\hline
\end{tabular}

To summarize the results, we can state that nurses of the Alekseev Psychiatric Hospital N1 have a much higher degree of self-concept (due to their age and relevant experience), $(t=-3.08, p=0.02)$, and the prevailing level on the following scales such as self-esteem $(\mathrm{t}=-3.43, \mathrm{p}=0.0)$, auto-sympathy ( $\mathrm{t}$ $=-2.84, p=0.0)$, self-confidence $(t=-4.90 p=0.0)$, self-understanding $(t=-2.29, p=0.02)$, and expected attitude of others $(t=-3.82, p=0.0)$.

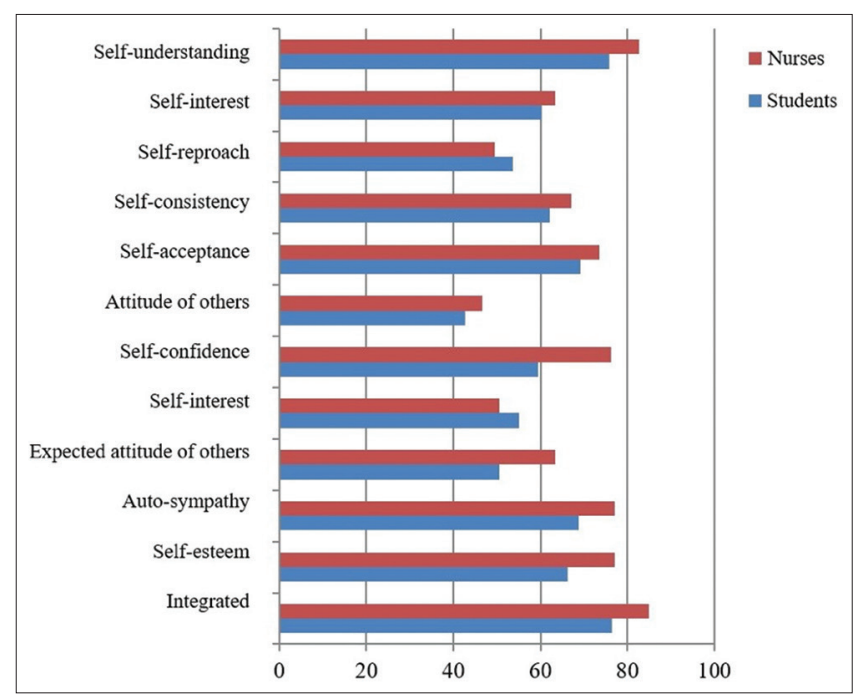

Figure 6: Self-concept questionnaire test (nurses vs. students)

Seashore test of nurses revealed significantly higher results on the following scales:

- $\quad$ Belonging to the group $(t=-2.06, p=0.04)$;

- $\quad$ Moving to another group $(t=-2.98, p=0.03)$;

- Relationship with management $(\mathrm{t}=2.92$, $\mathrm{p}=0.0)$;

- $\quad$ General index $(t=-2.21, p=0.02)$.

Thus, nurses feel the cohesion of the team to a greater extent than the $1^{\text {st }}$ year students, which, in general, comes naturally.

\section{Discussion}

The undertaken study proved the hypotheses we put forward: The development of the burnout syndrome is influenced by personal qualities of psychiatrists and nurses (residents and students), and the managerial features of their activities. Occupational burnout develops in psychiatrists and nurses over the course of their professional career, but it starts to emerge during their education.

We can, therefore, assert that the problem of occupational burnout in psychiatrists and nurses is important not only at the stage of personal realization at work but also at the time of obtaining the bachelor's degree or residency stage. Our research shows a significant evidence of occupational burnout in young people who are at the stage of obtaining medical degrees. 
Variables under the AWOB test show that general self-concept is an increasing problem for students and residents, while psychiatrists and nurses attach greater importance to the professional development and self-actualization.

Speaking about the FPI test diagnostics of states and personality traits that are of paramount importance for the process of social adaptation and regulation of behavior, we note that there is a significantly higher level of neuroticism, spontaneous aggressiveness, depression, and emotional lability among residents and students. In students, this is also complemented by a higher level of irritability and reactive aggressiveness, suggesting that young people are exposed to stress (related both to their education and entering into the profession) and, therefore, are much more neuroticized.

SCQ questionnaire reveals the following specifics of self-concept in psychiatrists and nurses of the Alekseev Psychiatric Hospital N1 - they have a significantly higher level of the integral feeling of one's own self, and higher scores on the scales such as self-esteem, auto-sympathy, self-confidence, selfunderstanding, and expected attitude of others (the latter scale being important for nurses only). We believe that higher scores are obtained due to greater professionalism and age. It is important to mention that the high reliability levels of the psychiatrists and residents are associated with the professional deformation of psychiatrists.

Determining the group cohesion using the Seashore index indicates a higher level of cohesiveness in residents as compared to that of psychiatrists. However, the results of nurses are higher than those of students, that is, residents rate their group as a more integral one than psychiatrists do, and nurses rate their group as a more integral one than students do. This is linked to working conditions - nurses work in a team (and interact with each other), while psychiatrists, although working together, rely on themselves rather than on the help of colleagues.

Efforts are required to reduce unnecessary stressors through changing the educational and clinical environments and creating more favorable ones instead. Destigmatizing psychological distress, promoting prevention, and recognition of burnout symptoms are critical factors in motivating medical students to seek help. Thus, a growing number of research studies over the past decade have raised awareness of burnout among professionals and students. Early intervention at the stage of the development of professional competencies of students (future nurses) and residents should be considered as a means of preventing the development of future occupational burnout and increasing the efficiency of current medical work.

Since 2011, School of Medicine of Saint Louis University (USA) has been pursuing a multifaceted strategy to address these problems in preclinical years, thus, helping to reduce the level of depression and anxiety symptoms in students.

There is a foreign experience of using the Balint group not only in the prevention of developed professional deformation of medical workers but also in teaching students of medical schools. The International Balint Congress in Heidelberg that took place in September 2013 addressed this important topic, including the application of the Balint group method in teaching undergraduate students as an efficient mechanism to respond to strong negative emotions that could threaten the sense of identity of medical students. Balint groups provide an opportunity to discuss clinical situations in a safe environment, thus, introducing students to their emotions and helping to develop understanding of them, to form adaptive ways of processing emotions that can lead to strengthening professional identity and preserving personal boundaries. Participation in the Balint group allows to achieve positive results, including significant improvements in many areas, as well as a decrease in occupational burnout. This experience can be also replicated in our country.

In view of the above, participation of students or residents in the Balint group at the onset of their medical practice could make them feel that they are not alone, there is a collective mutual support that "the patient making you furious" situation or surprisingly having the patient on your mind for a long time can happen. It is important to have a safe place where you can talk about it, go through a difficult situation, gain new understanding of what happened and find blind spots.

The study shows that the development of the burnout syndrome is influenced by personal qualities of psychiatrists and nurses (residents and students), and the managerial features of their activities. Occupational burnout is developed in psychiatrists and nurses over the course of their professional career, but it starts to emerge during their education; it is associated not only with occupational burnout risks but also with age and stress during their education. Students and residents are generally more neuroticized (as shown by the FPI test), they have lower self-concept (according to the SCQ test) than psychiatrists and nurses working in medical facilities. Thus, we can speak about a higher level of occupational burnout in relation to general self-concept and assessment of one's own work results (according to the AWOB Test). The Integrative Burnout Index shows the highest level of burnout in students of the [BLINDED] University, and nurses of the Alekseev Psychiatric Hospital N1, and the lowest level in psychiatrist of the same hospital. This means that despite being in the profession for a long time, psychiatrists have formed strategies to resist professional burnout in a stressful situation. 


\section{Research limitations}

The range of problems considered in this study is limited to the issues of occupational burnout in medical workers in psychiatry (nurses and psychiatrists) and residents of the Alekseev Psychiatric Hospital N1. Besides, students (future nurses) of the [BLINDED] University also participated in the study.

\section{Conclusions}

The problem of occupational burnout in medical students in higher educational institutions is a real obstacle to the development of their further professional career. The search for strategies to prevent occupational burnout while studying at a university and in residency remains an urgent problem. Today, practical researchers have demonstrated moderate efficiency of individual interventions aimed at this syndrome, but institutional and mixed ways to prevent burnout have not been adequately investigated yet.

Findings indicate the need to assist students and residents during their entry into the profession. Such an opportunity could be provided, for example, by the Balint groups for students and the Balint group leaders training course, which would make it possible to work in the future, and to apply knowledge gained during the residency and during the bachelor's program to prevent professional burnout when entering the profession. Dealing with occupational burnout during the education is important not only for any future medical workers but also for representatives of any caring professions, teachers, social workers, and practical psychologists, for all those who face immediate problems of clients or patients in their work. During the pandemic of the recent years, this has become a major problem for all those who provide assistance to the population.

\section{Ethics approval statement}

The authors declare that the work is written with due consideration of ethical standards. The study was conducted in accordance with the ethical principles approved by Sechenov First Moscow State Medical University.

\section{Patient consent statement}

The study was conducted by interviewing subjects that participated voluntarily.

\section{Data availability statement}

Data will be available on request.

\section{References}

1. Abramov VA, Alexeitshuk IS, Alexeitshuk Al. Study of burning out syndrome on the stage of meta-reviews. J Psychiatry Medical Psychol. 2008;1(18):117-23.

2. Korehova MV, Soloviev AG, Kirov M, Malyshki EA, Novikova IA. Occupational burnout syndrome at the psychiatrists anaesthetist. Messenger Anesthesiol Resusc. 2016;13(3):19-28. https://doi. org/10.21292/2078-5658-2016-13-3-19-28

3. Nowakowska $S$, Wolniewicz $Ł$. Professional burnout among nurses and paramedics. Higher Schools Pulse. 2017;11(2):22-5. https://doi.org/10.5604/01.3001.0010.1585

4. Wilczek-Rużyczka E, Zaczyk I, Obrzut K. Occupational burnout of palliative care nurses. Nurs Public Health. 2017;7(1):77-83. https://doi.org/10.17219/pzp/64031

5. Maslach C. Understanding burnout: Definitional issues in analyzing a complex phenomenon. In: Paine WS, editor. Job Stress and Burnout. Beverly Hills: Sage; 1982.

6. Boiko VV. Emotional Burnout Syndrome in Professional Communication. Saint-Petersburg: Sudarynya Publishing House; 2000.

7. World Health Organization. Primary Prevention of Mental Neurological and Psychosocial Disorders, Burnout. Ch. 5. Geneva: World Health Organization; 1998. p. 91-110.

8. Bukhtoyarov IV, Rubtsov MY. Occupational burnout: Manifestation and assessment criteria. Analytical survey. Bull Pirogov Natl Med Surg Center. 2014;9(2):106-11.

9. Jovanovic N, Beezhold J, Andlauer O, Kuzman MR, Podlesek A, Hanon C, et al. Burnout among psychiatry residents. Die Psychiatrie. 2009;6(2):75-9. https://doi. org/10.1055/s-0038-1671919

10. Frajerman A, Morvan Y, Krebs MO, Gorwood P, Chaumette B. Burnout in medical students before residency: A systematic review and meta-analysis. Eur Psychiatry. 2019;55:36-42. https://doi.org/10.1016/j.eurpsy.2018.08.006 PMid:30384110

11. Sirota NA, Yaltonsky VM, Yaltonskaya AV, Moskovchenko DV Emotional burnout among psychiatrists. Infect Dis News. 2017;4:19-25. https://doi.org/10.24411/2305-3496-2017-00063

12. Leiter MP, Maslach C. A mediation model of job burnout. In: Antoniou AS, Cooper CL, editors. Research Companion to Organizational Health Psychology. Cheltenham, United Kingdom: Edward Elgar; 2005, pp. 544-64.

13. Schaufeli WB, Maslach C, Marek T. Professional Burnout: Recent Developments in Theory and Research. London, United Kingdom: Routledge; 2017.

14. Agibalova AA, Ustimenko OA, Zenkina VG. Factors of medical school lecturers' occupational burnout. In: Murzina ZV, Bogatyreva OL, editors. Pedagogy and Psychology as the Sciences of Forming the Potential of Modern Society. Tamil Nadu: Publishing House Sreda; 2021. p. 116-29.

15. Zrazhevskaya IA, Bykov KV, Topka EO, Peshkin VN, Isaev RN Orlov AM. The evolution of representations about the syndrome of emotional burnout. Psikhiatriya. 2020;18(4):127-38. https:// doi.org/10.30629/2618-6667-2020-18-4-127-140

16. Bielan $O$, Kurnatowska $O$, Kurnatowska AJ. Occupational burnout among studying nurses. Clin Psychiatry Psychol. 2011;11(3):175-82.

17. Pruteanu LM, Robu V. Aspects of occupational burnout among nurses. In: International Conference of Scientific Paper AFASES 2015. Vol. 1. Telangana: Publishing House of Henri Coanda, Air Force Academy; 2015. p. 287-92.

18. Ito JK, Brotheridge CM. Resources, coping strategies, and emotional exhaustion: A conservation of resources perspective. J Vocat Behav. 2003;63:490-509. 
19. Wilk SL, Moynihan LM. Display rule "regulators": The relationship between supervisors and worker emotional exhaustion. J Appl Psychol. 2005;90(5):917-27. https://doi. org/10.1037/0021-9010.90.5.917

20. Alamri R, Nasser A, Zisook S. Medical student and physician burnout in the Gulf region: A systematic review. Int J Psychiatry. 2020;5(2):36-53.

21. Wake C. Is it occupational burnout or stress? Dent Nurs. 2018;14(8):372-3. https://doi.org/10.12968/denn.2018.14.8.372

22. Ognerubov NA, Karpova EB. Emotional burnout syndrome among psychiatrists and students in medical universities. Vol. 22. In: Tambov University Reports. Series: Natural and Technical Sciences; 2017. p. 221-31. https://doi. org/10.20310/1810-0198-201722-1-221-231

23. Bardenshtein LM, Kekelidze ZI, Makushkin EV, Danilova SV, Panchenko EA, Borodin VI. Modern educational process of psychiatrist training. Russ Psychiatric J. 2015;5:4-11.

24. Petrova NN. Preparing the specialists in the field of psychiatry: Problems and prospects. Bull St Petersburg Univ Med. 2014;11(1):250-9.

25. Dyrbye L, Shanafelt T. A narrative review on burnout experienced by medical students and residents. Med Educ. 2016;50(1):132-49. https://doi.org/10.1111/medu.12927 PMid:26695473

26. Arnone R, Cascio MI, Parenti I. The role of emotional intelligence in health care professionals burnout. Eur J Public
Health. 2019;29(4):ckz186.553. https://doi.org/10.1093/eurpub/ ckz186.553

27. Vlachou EM, Damigos D, Lyrakos G, Chanopoulos K, Kosmidis G, Karavis M. The relationship between burnout syndrome and emotional intelligence in healthcare professionals. Health Sci J. 2016;10(5):1-9. https://doi. org/10.4172/1791-809X.1000100502

28. Avagimyan AA, Kasimovskaya NA. Balint Groups as a method to prevent occupational stress of psychiatry nursing staff. In: Compendium of the British Balint Society. Council of the British Balint Society; 2018. p. 73-81.

29. Avagimyan AA, Krasnyuk II, Kasimovskaya NA, Ulianova NA, Pryazhnikova EY, Matanis VA. Balint groups as a method to prevent stress in mental health workers. Opción 2020;36(27):11-28

30. Vinokur VA, Klitsenko OA. Validation of the methodology for psychological diagnostics of professional "burnout" in "helping" professions (the "OPRV" questionnaire). Med Psychol Russ Electron Sci J. 2012;1:12.

31. Glukhanyuk NS. Tutorial on Psychodiagnostics: Textbook. $2^{\text {nd }}$ ed. Moscow: Publishing House of Moscow Psychological and Social Institute; 2005.

32. Vansovskaya LI, Gayda VK, Gerbachiovski VK, Krylov AA. Tutorial on Experimental and Practical Physiology, Textbook. Saint-Petersburg: Publishing House of Saint-Petersburg University; 1997. 